\title{
Intelligent Speed Regulation Control in Switched Reluctance Motor of Electric Vehicle Based on Neural Network Parameter Identification
}

\author{
Huang Zongjian* \\ Henan Polytechnic Institute,Nanyang, Henan, China \\ *Corresponding Author.
}

\begin{abstract}
:
This paper studies the intelligent speed regulation control of switched reluctance motor of electric vehicle based on neural network parameter identification. Starting with the analysis of the performance of switched reluctance motor, the nonlinear flux linkage characteristic inversion model and torque characteristic model of switched reluctance motor are established based on BP neural network. This paper studies and improves the fast self configuration algorithm of BP neural network. Finally, the nonlinear simulation model of switched reluctance motor is established under Matlab/Simulink. The model can be used for further control research. In this paper, the integrated control method of instantaneous torque control based on torque observation and three-step commutation control is studied, and the simulation analysis is carried out. The results show that this method can effectively reduce the torque ripple of switched reluctance motor and improve the performance of its drive system.
\end{abstract}

Keywords: Neural Network, Parameter Identification, Switched Reluctance, Intelligent Speed Regulation Control.

\section{INTRODUCTION}

Electric vehicle is a high-tech electromechanical product integrating automobile technology, motor technology, battery technology, aerodynamics, computer technology, control technology, new material technology and human engineering [1-2]. There are several key technologies in the research and development of electric vehicles, such as battery technology, motor drive and control technology, electric vehicle technology, electronic control technology and so on. Their technical indicators directly affect the performance of electric vehicles [3]. The drive system is 
Article History: Received: 28 October 2021 Revised: 05 December 2021 Accepted: 10 January 2022 Publication: 28 February 2022

mainly divided into three parts: energy supply subsystem, electrical drive subsystem and mechanical transmission subsystem [4]. The motor drive system in the electrical drive subsystem is mainly composed of motor, power electronic converter, digital controller and sensor. It is the heart of electric vehicle [5].

As a driving motor, switched reluctance motor has many remarkable characteristics and occupies a certain proportion in the driving motor for electric vehicles. However, the torque ripple and large noise determined by its own structure hinder its further application in electric vehicles [6-7]. This problem can be solved from two main aspects: on the one hand, the switched reluctance motor is optimized and improved in structure; On the other hand, from the control point of view, high-performance control methods are used to reduce the torque ripple and noise of switched reluctance motor. The research and design of this paper is the low torque ripple control system of switched reluctance motor for electric vehicle.

\section{SWITCHED RELUCTANCE MOTOR DRIVE SYSTEM}

\section{Composition of switched reluctance motor drive system}

SR motor is an electromechanical energy conversion device. According to the reversible principle, SR motor can convert electrical energy into mechanical energy, that is, electric operation, and mechanical energy into electrical energy, that is, power generation operation. Its structure and working principle are very different from the traditional AC / DC motor. The structure of SR motor is simple [8]. The magnetic poles of its stator and rotor are salient pole structure. In principle, it is a kind of variable reluctance stepping motor. The salient poles of the stator and rotor are laminated by ordinary silicon steel sheets. The rotor has neither windings nor permanent magnets [9]. There are concentrated windings on the stator. Two radially opposite windings are connected in series to form a two pole magnetic pole, which is called one phase [10]. SR motor can be divided into single-phase, two-phase, three-phase and multiple equal and different phase number structures according to different phase numbers, and each pole single tooth structure and each pole multi tooth structure, axial air gap, radial air gap and axial radial mixed air gap structure, inner rotor and outer rotor structure. See Table 1 for common combination schemes of stator and rotor poles.

TABLE I. Pole number combination of stator and rotor of common SR motor

\begin{tabular}{|c|c|c|c|c|c|c|c|c|c|}
\hline NUMBER OF PHASES M & $\mathbf{1}$ & $\mathbf{2}$ & $\mathbf{3}$ & $\mathbf{4}$ & $\mathbf{5}$ & $\mathbf{6}$ & $\mathbf{7}$ & $\mathbf{8}$ & $\mathbf{9}$ \\
\hline $\begin{array}{c}\text { NUMBER OF STATOR } \\
\text { POLES NS }\end{array}$ & 2 & 4 & 6 & 8 & 10 & 12 & 14 & 16 & 18 \\
\hline $\begin{array}{c}\text { NUMBER OF ROTOR } \\
\text { POLES NR }\end{array}$ & 2 & 2 & 4 & 6 & 8 & 10 & 12 & 14 & 16 \\
\hline
\end{tabular}


Power converter is a switching component connecting power supply and motor winding in SRD. Through it, the power energy is fed into the motor, and the magnetic field energy storage in the motor can also be fed back to the power supply. Because the winding of SR motor only needs one-way current, the main circuit of its power converter is not only simple, but also has the advantages that ordinary AC and brushless DC drive systems do not have, that is, the phase winding is connected in series with the main switching device, so it can prevent short-circuit fault. In the whole cost of SRD, power converter accounts for a large proportion. Reasonable selection and design of power converter is one of the keys to improve the performance price ratio of SRD. The design and selection of the main switching device of the power converter and the selection of the main circuit form of the power converter are very important. The best combination scheme should be found according to the specific performance, place of use and other aspects.

The controller comprehensively processes the motor rotor position, speed, current and other feedback information provided by the position detector and current detector and the external input instructions to control the running state of SR motor. It is the command center of SRD. The controller is generally composed of single chip microcomputer or DSP chip and peripheral interface circuit, which can be used to realize the comparative analysis of motor parameters and the operation of control algorithm. In SRD system, the controller is required to realize the following functions: (1) current chopping control; (2) Angle position control; (3) Start, control, stop and four quadrant operation: (4) speed regulation. High performance controller combined with effective motor control strategy can reduce torque ripple and noise, and improve the speed regulation performance of motor.

2.Working principle and operating characteristics of switched reluctance motor

When the phase a winding current control switches S1 and S2 are closed, the phase A is excited, and the generated magnetic field rotates the rotor to the position where the rotor pole axis coincides with the phase a stator pole axis, that is, the position shown in the figure, so as to generate an electromagnetic torque with magnetoresistive properties. When the four phase windings of the stator are energized in sequence, the rotor will rotate continuously in the corresponding sequence. During the actual operation of polyphase motor, two or more windings are often connected at the same time.

Due to the electromagnetic torque with magnetoresistive property, the steering of SR motor is independent of the current direction of phase winding and only depends on the energization sequence of phase winding, which makes it possible to fully simplify the power converter circuit. When the main switches S1 and S2 are on, the phase a winding absorbs electric energy from the DC power supply U. when S1 and S2 are off, the winding current feeds back the residual energy to the power supply u through the freewheeling diodes VD1 and VD2. Therefore, SR motor has the characteristics of energy feedback and high system efficiency. 
Article History: Received: 28 October 2021 Revised: 05 December 2021 Accepted: 10 January 2022 Publication: 28 February 2022

The operating characteristics of switched reluctance motor can be divided into three areas: constant torque area, constant power area and natural characteristic area (series excitation characteristic area).

Switched reluctance motor generally operates in constant torque area and constant power area. In these two areas, the actual operating characteristics of the motor are controllable. By controlling the conditions, any actual operating characteristics below the solid line can be realized. Under the first critical speed base speed wb, the motor outputs a constant torque, in order to limit the electromagnetic max and the current I does not exceed the allowable values of the motor and controllable switching devices. The applied voltage $u$ and three controllable variables, namely the switching angles $\theta$ on and $\theta$ off, should be adjusted. At this time, the Current Chopping Control (CCC) is generally adopted, which firstly fixes the switching angles $\theta$ on and $\theta$ off, and then further controls the effective value of the applied voltage through chopping.

\section{MODELING OF SWITCHED RELUCTANCE MOTOR SYSTEM}

1.Basic equation of switched reluctance motor

For k-phase SR motor, when hysteresis, eddy current and mutual inductance between windings are not considered, like the operation theory of other electromagnetic electromechanical devices, the dynamic process of its electromechanical system can be described by circuit equation, mechanical equation and electromechanical connection equation. According to the circuit law, the single-phase voltage balance equation of SR motor can be obtained:

$$
U_{k}=R_{k} i_{k}+\frac{d \psi_{k}}{d t}
$$

Where: Uk is the voltage at both ends of phase $\mathrm{k}$ winding; $\mathrm{Rk}$ is the resistance of $\mathrm{k}$-phase winding; ik is the current of k-phase winding; $\psi \mathrm{k}$ is the flux linkage of $\mathrm{k}$-phase winding.

In general, $\psi \mathrm{k}$ is winding current $\mathrm{ik}$ and rotor displacement angle $\theta$ The flux linkage can be expressed by the product of inductance and phase current, ignoring the mutual inductance between phases, that is, it can be expressed as:

$$
\psi_{k}=\psi_{k}(i, \theta)=L_{k}\left(\theta_{k}, i_{k}\right) \times i
$$

Substitute into equation (1):

$$
U_{k}=R_{k} i_{k}+\frac{\partial \psi_{k}}{\partial i_{k}} \frac{d i_{k}}{d t}+\frac{\partial \psi_{k}}{\partial \theta} \frac{d \theta}{d t}
$$

Where: the first term is the resistance voltage drop in the k-phase circuit; the second term is 
Article History: Received: 28 October 2021 Revised: 05 December 2021 Accepted: 10 January 2022 Publication: 28 February 2022

the electromotive force induced by the change of flux linkage caused by current change, also known as transformer electromotive force; The third item is the electromotive force induced by the change of flux linkage in the winding caused by the change of rotor position, also known as moving electromotive force, which is directly related to the energy conversion of electromagnetic machinery. When the electromagnetic torque te of the motor is not equal to the load torque acting on the motor shaft, there will be acceleration and the speed will change. The mechanical equation of the motor is obtained from the mechanical law:

$$
T_{e}=J \frac{d \omega}{d t}+F \omega+T_{l}
$$

2.Nonlinear neural network model of switched reluctance motor

The input variable of switched reluctance motor torque model is rotor position angle $\theta$ And phase winding current $\mathrm{I}$, output torque t. Therefore, the initial structure of the network is to input two nodes and output one node. A single hidden layer is adopted, and the number of hidden layer nodes is 55. Training samples are the premise of successfully using BP neural network for model identification. In order to train the torque model of SR motor, the number of sample points in rotor position angle direction and phase current direction should be determined first.

Because each phase of SR motor is independent and symmetrical, the relationship between one phase torque and phase current and the position angle of half rotor pole distance can be selected to prepare sample data. The fast self configuration training algorithm of the network is programmed with MATLAB. The target error e of the initial training parameter of the algorithm is 0.0001 , the error threshold of self configuration learning is 0.005 , the threshold values of correlation coefficient and dispersion are 0.9 and 0.001 respectively, the maximum number of learning times is 3000 , and the lower limit node number $\mathrm{n}$ of hidden layer is 9 .

In the training process, in order to get good results, the sample data are normalized, the outliers are eliminated, and several groups of different initial conditions are used to train the network, and then the best result is selected. After the above processing, the trained network has strong generalization ability, and the BP network avoids falling into local minimum, and the network effect is good.

From the simulation results and the verification effect diagram, it can be seen that the fast self configuration algorithm combined with Levenberg Marquardt algorithm and improved self configuration algorithm is used to train the BP network. The established switched reluctance motor torque model has good stability, high accuracy and strong generalization ability. At the same time, the training convergence of the network is fast. The trained network has a small scale and can be used for real-time control. It creates conditions for further optimizing SRM energy conversion and reducing torque ripple.

In the training process, the number of hidden layer nodes deleted each time and their serial 
Article History: Received: 28 October 2021 Revised: 05 December 2021 Accepted: 10 January 2022 Publication: 28 February 2022

numbers can be seen in Table 2 .

TABLE II. Delete node list

\begin{tabular}{|c|c|c|}
\hline $\begin{array}{c}\text { DELETION } \\
\text { NUMBER }\end{array}$ & $\begin{array}{c}\text { TOTAL NUMBER } \\
\text { OF DELETED } \\
\text { NODES (PCS.) }\end{array}$ & DELETE NODE SERIAL NUMBER \\
\hline FIRST DELETE & 11 & 10、14、17、19、20、21、22、23、24、25、29 \\
\hline FIRST DELETE & 10 & 32、37、38、42、46、48、49、51,52 \\
\hline $\begin{array}{c}\text { SECOND } \\
\text { DELETION }\end{array}$ & 4 & 4、13、14、20 \\
\hline $\begin{array}{c}\text { THIRD } \\
\text { DELETION }\end{array}$ & 1 & 12 \\
\hline $\begin{array}{c}\text { FOURTH } \\
\text { DELETION }\end{array}$ & 1 & 16,23 \\
\hline $\begin{array}{c}\text { FIFTH } \\
\text { DELETION }\end{array}$ & 2 & 9,12 \\
\hline $\begin{array}{c}\text { SIXTH } \\
\text { DELETION }\end{array}$ & 2 & 18,24 \\
\hline $\begin{array}{c}\text { SEVENTH } \\
\text { DELETION }\end{array}$ & 2 & \multicolumn{2}{|c|}{} \\
\hline
\end{tabular}

\section{SIMULATION MODEL OF INTEGRATED CONTROL STRATEGY}

The simulation model of integrated control strategy used in this paper mainly has four modules: speed regulation module, torque observation module, torque regulation module and SRM module.

The speed regulation module is based on the given speed $\mathrm{w}_{\text {ref }}$ and the actual speed. The reference torque $\mathrm{T}_{\text {ref }}$ is obtained. From the mechanical equation of the motor, it can be deduced that:

$$
J \frac{d \omega}{d t}=T_{e}-F \omega-T_{l}
$$

It can be seen from the above formula that when the speed is constant, the output torque is constant and equal to the sum of load torque and friction loss. Define for this purpose:

$$
\Delta T_{e}=J \frac{d \omega}{d t}
$$

When the time interval is small enough, it can be considered that:

$$
\Delta T_{e}=\frac{J}{\Delta t} \sqcap \Delta \omega=K_{p} \Delta \omega(7)
$$


Article History: Received: 28 October 2021 Revised: 05 December 2021 Accepted: 10 January 2022 Publication: 28 February 2022

It can be seen that the torque deviation can be obtained by multiplying the speed deviation by a scale factor. Considering the need to eliminate the steady-state error of the system and adjust the dynamic process of the system to make the system have good dynamic and static performance, the integral factor and differential factor are introduced to construct PID. Conventional PID is mostly used to control linear objects, and its regulation ability for nonlinear objects is limited. Therefore, adaptive fuzzy PID is used as speed regulator in this paper.

In this paper, the current regulation module is realized by current hysteresis loop. Its function is to control the on and off of the switching device of the power converter according to the deviation between the given current and the actual current, so as to change the polarity of the output voltage. When the deviation value exceeds the upper limit of hysteresis, a positive voltage is output, otherwise a negative voltage is output. Through the comparison and adjustment of the current regulator, the actual current will change zigzag around the reference current waveform, and the deviation will be limited within the specified range to ensure that the actual current tracks the given current.

The feedback speed calculation module is realized by the differential module of MATLAB / Simulink, that is, the feedback speed is obtained by deriving the angle value of the output SR motor. In this system, not only the current of the current control phase but also the current of the observation phase should be output. Therefore, this paper designs the current detection output module, that is, the current output is determined according to the above commutation logic relationship.

\section{CONCLUSION}

Switched reluctance motor drive system is a new type of variable speed motor drive system, which has many remarkable advantages. It has been applied in many fields and also occupies a place in the motor drive system for electric vehicles. However, due to the double salient structure of switched reluctance motor and the use of switching power supply, noise and vibration are serious problems, which restricts the application and development of switched reluctance motor in electric vehicles and other fields. Therefore, based on the comprehensive summary of relevant literature at home and abroad, combined with the instantaneous torque control method based on torque observation and three-step commutation method, this paper controls the switched reluctance motor to reduce the torque ripple and noise of the switched reluctance motor, and designs the control system.

\section{REFERENCES}


Article History: Received: 28 October 2021 Revised: 05 December 2021 Accepted: 10 January 2022 Publication: 28 February 2022

1. FA-WANG Y E , DE-CHANG L.: Application of High Resolution Satellite Remote Sensing Technology in Identification and Analysis of the Uranium Mineralization Bleached Alteration. Remote Sensing for Land \& Resources, 2012, 24(4):232-232.

2. VADREVU K P , LASKO K, GIGLIO L.: Analysis of Southeast Asian pollution episode during June 2013 using satellite remote sensing datasets. Environmental Pollution, 2014, 195:245-256.

3. ZORAN M, ZORAN L F, DIDA A.: Satellite remote sensing image based analysis of effects due to urbanization on climate and health. Proceedings of SPIE - The International Society for Optical Engineering, 2013, 8893(6):909-927.

4. ELGAFY, ANWAR M.: Environmental Impact Assessment of Transportation Projects: An Analysis Using an Integrated GIS, Remote Sensing, and Spatial Modeling Approach. Environmental Modelling \& Software, 2005, 79(C):85-95.

5. VIRTANEN T, MIKKOLA K, NIKULA A.: Satellite image based vegetation classification of a large area using limited ground reference data: A case study in the Usa Basin, north-east European Russia. Polar Research, 2006, 23(1):51-66.

6. YANG X, ZHENG Y, GENG G.: Development of PM 2.5, and NO2, models in a LUR framework incorporating satellite remote sensing and air quality model data in Pearl River Delta region, China. Environmental Pollution, 2017, 226:143-153.

7. FERRIER G.: Application of Imaging Spectrometer Data in Identifying Environmental Pollution Caused by Mining at Rodaquilar, Spain. Remote Sensing of Environment, 1999, 68(2):125-137.

8. LEIFER I , MELTON C , TRATT D M.: Remote sensing and in situ measurements of methane and ammonia emissions from a megacity dairy complex: Chino, CA. Environmental Pollution, 2017, 221:37-51.

9. WU X, LIU T , CHENG Y.: Dynamic monitoring of straw burned area using multi-source satellite remote sensing data. Transactions of the Chinese Society of Agricultural Engineering, 2017, 33(8):153-159.

10. HUANG Y, ORGAN B , ZHOU J L.: Emission measurement of diesel vehicles in Hong Kong through on-road remote sensing: Performance review and identification of high-emitters. Environmental Pollution, 2018, 237:133-142. 